Issued by Sandia National Laboratories, operated for the United States Department of Energy by Sandia Corporation.

NOTICE: This report was prepared as an account of work sponsored by an agency of the United States Govemment. Neither the United States Government, nor any agency thereof, nor any of their employees, nor any of their contractors, subcontractors, or their employees, make any warranty, express or implied, or assume any legal liability or responsibility for the accuracy, completeness, or usefulness of any information, apparatus, product, or process disclosed, or represent that its use would not infringe privately owned rights. Reference herein to any specific commercial product, process, or service by trade name, trademark, manufacturer, or otherwise, does not necessarily constitute or imply its endorsement, recommendation, or favoring by the United States Government, any agency thereof, or any of their contractors or subcontractors. The views and opinions expressed herein do not necessarily state or reflect those of the United States Government, any agency thereof, or any of their contractors.

Printed in the United States of America. This report has been reproduced directly from the best available copy.

Available to DOE and DOE contractors from

Office of Scientific and Technical Information

P.O. Box 62

Oak Ridge, TN 37831

Prices available from (703) 605-6000

Web site: http://www.ntis.gov/ordering.htm

Available to the public from

National Technical Information Service

U.S. Department of Commerce

5285 Port Royal Rd

Springfield, VA 22161

NTIS price codes

Printed copy: A03

Microfiche copy: A01

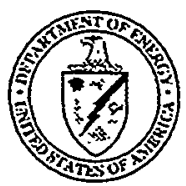




\section{DISCLAIMER}

\section{Portions of this document may be illegible in electronic image products. Images are produced from the best available original document.}


SAND 99-1318

Unlimited Release

Printed June 1999

\title{
Rapid Tooling via Investment Casting and Rapid Prototype Patterns
}

\author{
Michael D. Baldwin \\ Liquid Metal Processing Laboratory \\ Sandia National Laboratories \\ P.O. Box 5800 \\ Albuquerque, NM $\cdot 87185-1134$
}

\begin{abstract}
The objective of this work to develop the materials processing and design technologies required to reduce the die development time for metal mold processes from 12 months to 3 months, using die casting of $\mathrm{Al}$ and $\mathrm{Mg}$ as the example process. Sandia demonstrated that investment casting, using rapid prototype patterns produced from Stereolithography or Selective laser Sintering, was a viable alternative/supplement to the current technology of machining form wrought stock. A demonstration die insert (ejector half) was investment cast and subsequently tested in the die casting environment. The stationary half of the die insert was machined from wrought material to benchmark the cast half. The two inserts were run in a die casting machine for 3,100 shots of aluminum and at the end of the run no visible difference could be detected between the cast and machined inserts. Inspection concluded that the cast insert performed identically to the machined insert. Both inserts had no indications of heat checking or degradation.
\end{abstract}




\section{Rapid Tooling via Investment Casting and Rapid Prototype Patterns}

\section{Introduction}

Traditionally, all die cast tooling is machined from wrought Premium H-13 tool steel. Component testing and evaluation requires the use of numerous production-intent prototype castings. For large metal parts such as transmission cases, it currently may take as long as 18 months to build the mold to produce a single prototype part. Currently, the components are produced by sand or plaster casting processes. The resulting prototype part does not have the same performance characteristics as an actual production component produced by die casting. By introducing prototype die casting components produced from rapid tooling into the design/development process early, development time of cast metal parts can be significantly reduced. In addition, the die casting production process can get an early snapshot of production system requirements and design flaws can be eliminated. Both significantly improve national competitiveness in manufacturing.

As part of the "Rapid Tooling for Functional Prototyping of Metal Mold Processes" CRADA, between the United States Automotive Materials Partnership (USAMP) and Sandia National Laboratories, it was proposed that the use of new technologies, such as stereolithography, could be coupled with the investment casting process to produce dies rapidly. An oilpump cover die insert was selected as the test vehicle to demonstrate the concept. The insert design was an actual production insert supplied by Saturn/General Motors that is currently manufactured by machining wrought product. In production, the insert is set in a holding block that is then put into a die casting machine and molten aluminum is injected against the insert to produce the oilpump cover. It is believed in the die casting industry that inserts that have been cast, have degraded properties that cannot survive the harsh environment of die casting. Therefore, the investment cast insert half was mated against a machine wrought insert half and was tested in a die casting machine.

\section{Process and Observations}

\section{Electronic CAD File}

The electronic $\mathrm{CAD}$ file for the insert was supplied by Saturn, through EXCO Engineering. The file was created in CATIA and had to be converted to IGES in order to be used at Sandia in ProEngineer. EXCO also created a .stl (stereolithography) file for use by the rapid prototyping machines (3D Stereolithography and DTM Selective Laser Sintering). The conversion from CATIA to IGES was not a seamless process. Some of the complex 
geometric requirements were compromised, resulting in holes and geometric mismatches in the $\mathrm{CAD}$ file. The severity of the problems depends on how demanding the solid model package is. ProEngineer is a demanding package and a lot of work had to be performed to create a $\mathrm{CAD}$ file which possessed all the geometric requirements.

The conversion problem also caused geometric problems within the software used at Sandia for CMM measurement paths and visualization. The Sandia CMM software package is SILMA CMM Station Inspection. The combination of reconstructing the bad geometric features in the solid model and upgrading the SILMA software enabled visualization of the CMM data.

\section{Rapid Prototype Pattern}

The pattern needed for investment casting was built in the SLA 500 Stereolithography (SLA) machine. The build style used was QuickCast 2.0. The Stereolithography rapid prototype process was chosen based on casting trials performed earlier in the project. The process produced the most accurate patterns and, thus, castings and also the best surfaces. The support structure used in the build was all on the bottom surface, easy to remove, and did not cause any build artifacts. The cavity of the insert creates a problem known as a trapped. During the build, the volume of the cavity is filled with uncured resign which is subsequently pushed ahead of the wiper. This manifested itself as a slight positive deviation on the up facing surface, as shown in the cavity region in Figure 1. The problem could be avoided by building the part on an angle, however, this would create excessive build lines in the cavity and thus degrade the quality of the surface. Another possible solution would be the Zepher Recoating System now available on the newer 3D SLA machines. The Zepher was developed to minimize the trapped volume problem. The thickness of the part is also of concern, but is more of a casting issue and will be discussed in the next section.

\section{Investment Casting}

The simple geometric properties of this insert suggest that machining would be more attractive than casting. The insert is a nice rectangular, thick shape (the form of most wrought product) with long flat surfaces with all details in a direct line of sight and readably accessible. Casting should be used when the geometric complexities of the part dictate that machining becomes impossible if not cost prohibitive.

The SLA pattern was incorporated directly into the investment casting process as a consumable pattern that replaces the traditional wax pattern. After the SLA pattern and wax gates are invested, they are removed in a flash fire dewax furnace. The insert was then cast out of Premium H-13 tool steel in a vacuum furnace. The furnace was at 2-10 millitorr before melt in and then brought to 100 torr with argon when melting began. This 
over pressure of argon ensures that the elements with higher volatility are not lost from the alloy during the melting process. Because of the thickness of the insert, the investment shell was placed on a water cooled copper platen during casting to force directional solidification. This was necessary to drive the solidification shrinkage out of the insert and up into the gate. Radiographic inspection confirmed that this strategy was effective as no evidence of shrinkage voids could be detected in the cast insert. The flatness of the insert lead to undesirable dimensional deviations if the form of curling. The curling is a result of the residual stresses that were created on the flat face when the insert was solidified in the directional manner.

Another concern is the thickness of the insert and the resulting microstructural/mechanical properties in the center of the insert. The thickness leads to coarsening of the carbides towards the center of the insert, thus, degrading the mechanical properties of the overall insert. This issue needs to be addressed as larger parts are explored with Precision Castparts Corporation (PCC). PCC was the industrial partner identified and developed by Sandia for this project.

\section{Heat Treatment}

The as-cast insert was sent to Bodycote IMT, Inc. to be hot isostatically pressed (HIP). The cycle was $2200 \pm 25 \mathrm{~F}$ at $14750 \pm 250$ psi for 3 hours. This process serves two functions. First it closes any solidification shrinkage porosity that is not surface connected. This not only enhances the reliability of the casting, but usually increases the mechanical properties, especially toughness. Second, the HIP serves as the first step in the heat treatment cycle, homogenization.

After HIPing, the insert was sent to Kee Services, Warren, MI to for austenization and tempering. The austenization was performed at $1875 \mathrm{~F}$ for $2.5 \mathrm{hrs}$, air cooled. The insert was triple tempered for $4 \mathrm{hrs}$. each, all followed by an air cool. The tempers were at $1120 \mathrm{~F}$, $1140 \mathrm{~F}$, and 1080F, respectively. The final hardness was $39.4 \mathrm{HRC}$.

\section{Dimensional Properties}

Relevant dimensional information was recorded at each step of the process using a Zeiss UPMC 550 coordinate measuring machine (CMM). Data from the CMM were processed with a software package called "SILMA CMM Station Inspection," resulting in figures of the type shown in this report. Measurements were made on the SLA pattern, the as-cast insert, the HIPed insert, and the heat treated insert. Figures 1-4 are visual representations of the data with the deviations from nominal recorded as vectors. The green vectors represent deviations up to 0.010 ", yellow up to 0.020 ", and red up to 0.028 ".

As seen in Figure 1, the SLA pattern is fairly accurate. The only problem being the yellow region in the cavity, which is most likely caused by the trapped volume phenomena 
discussed above. In general, the SLA process builds a pattern with an accuracy of \pm 0.005 in. within an 8 in. diameter. For anything greater than 8 in., add 0.001 in./in. The surface shown in all the following figures, was the up-facing surface during the SLA build.

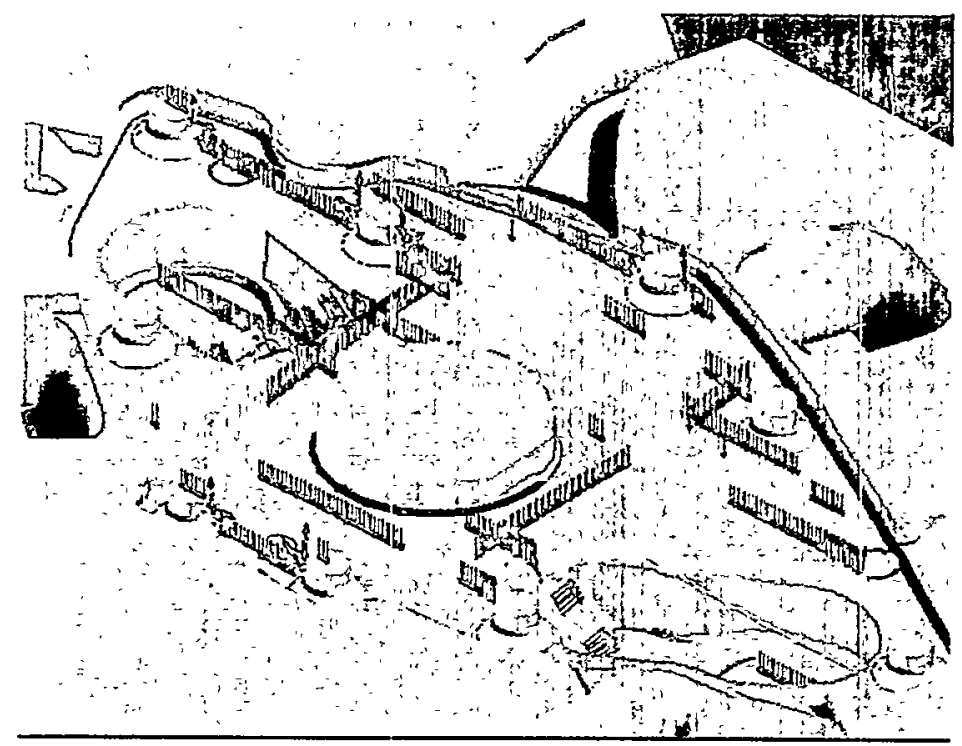

Figure 1: CMM data of the SLA pattern.

Most of the dimensional change in the entire process happens in the casting process. When comparing Figure $1 \& 2$, the general trend of the data stays the same, with the casting increasing the magnitude of the deviations approximately 0.005 ". This illustrates that castings should be treated as "near net shape" in tooling applications where the tolerances are very tight. However, cast insert become very attractive in complex geometries where the tolerances may be relaxed. This is an important consideration that should be addressed in the design stage of the tool and not in the fabrication. 


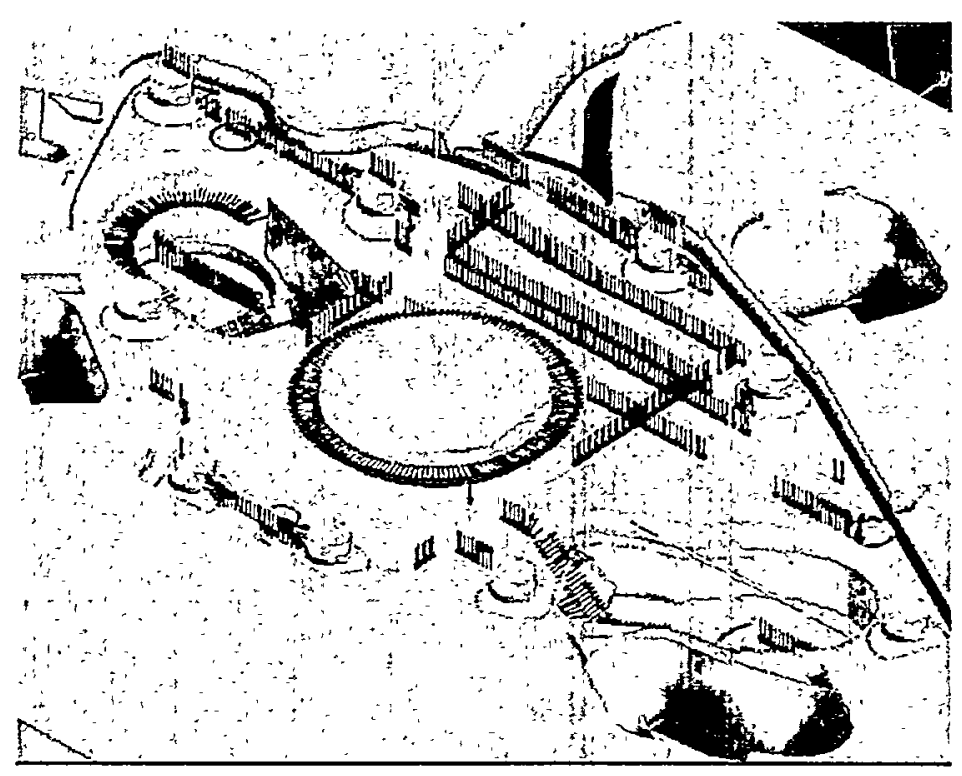

Figure 2: CMM data of the as-cast insert.

When comparing Figures $2 \& 3$, one can see that the HIPing process has a slight to no effect on the deviations in the part. Figures $3 \& 4$ are zoomed out further than Figures $1 \& 2$ to illustrate the curling effect that occurs on the top edge. The curling was discussed in the previous casting section. The surface shown for the casting, was the down facing surface in contact with the copper chill plate.

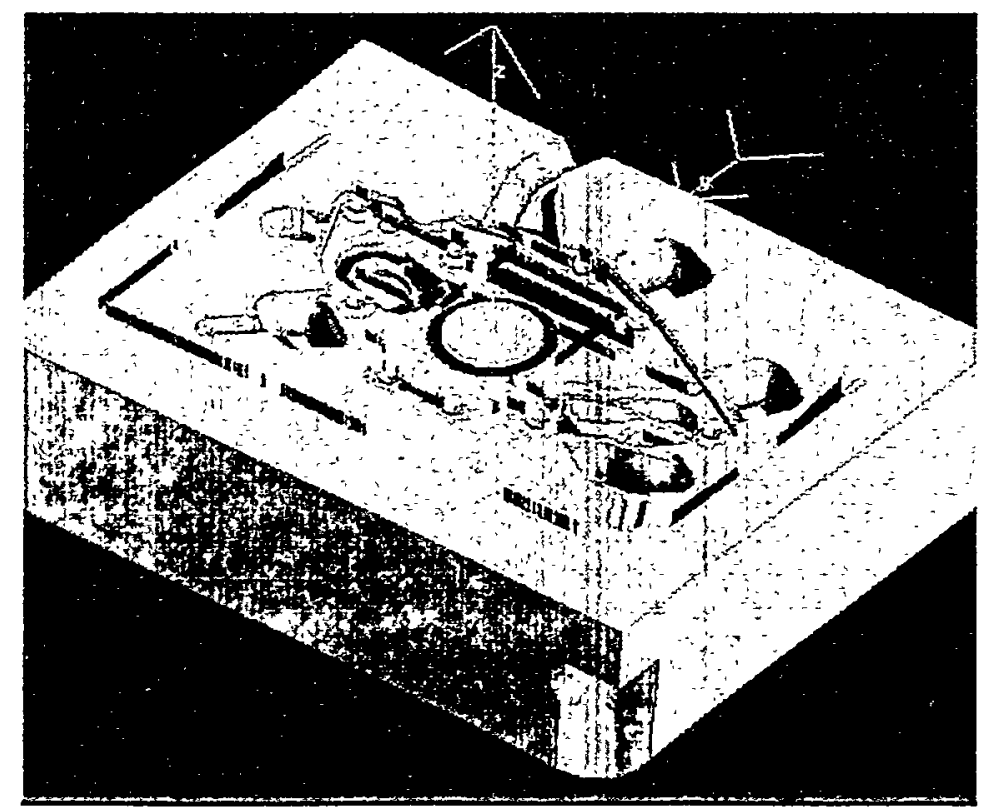

Figure 3: CMM data of the HIPed insert. 
Finally, when comparing Figures $3 \& 4$, one can see that again, there is little to no change during the heat treating cycles.

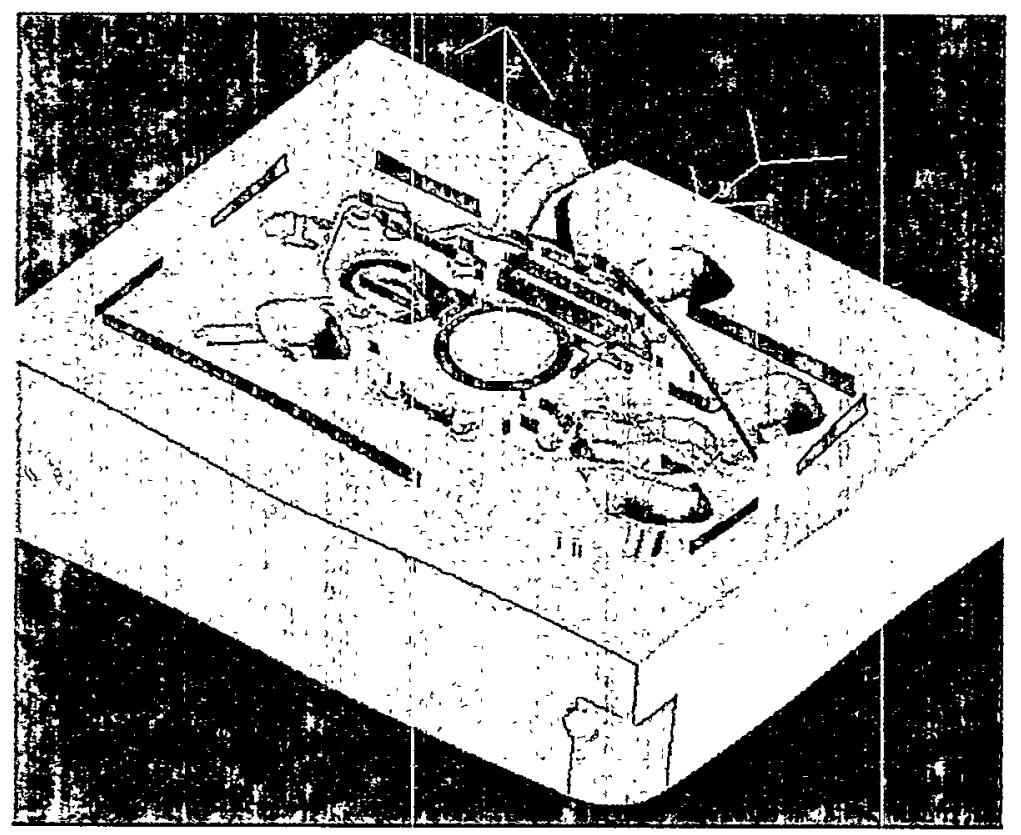

Figure 4: CMM data of the heat treated insert.

\section{Testing of Insert}

\section{Thermal Fatigue}

Before Sandia National Laboratories was selected to proceed with casting the insert, USAMP required an "pre-qualification" that the proposed process would work. This prequalification was provided in the form of a standardized thermal fatigue test. Using the same process steps that were described above, a 2 " $\mathrm{x} 2$ " $\times 7$ "casting with a 1.25 " diameter hole running through it was made. Once made, the casting was tested by Case Western University by dunking it repetitively into a molten pot of aluminum while periodically inspecting the corners for thermal fatigue cracks. When compared to a wrought/machined box put through the same testing, the casting performed comparable to, but not as well as the wrought product. Based on this result, it was decided to proceed with the insert. Further, while the dunk test provides valuable information, it does not fully simulate the 
die casting process. Therefore, the insert was tested not only for thermal fatigue, but for overall robustness and performance in an actual die casting unit.

\section{Die Casting}

The heat-treated insert was sent to Atols Tool and Mold Corporation for preparation for the die cast testing. The investment cast insert was the ejector half in the die casting operation. Atols fabricated a holding block for the cast insert and machined the cooling paths and the exterior sides of the insert to match the holding block, Fig. 5. The cavity surface of the cast insert was not touched and left in the as-cast condition. The only thing done to cavity was a simple sand blast. Atols then machined the stationary half of the insert from wrought material so that a direct comparison of the cast versus wrought/machined inserts could be made at the end of the run, Fig 6. The insert set was sent to Able Die Casting Corporation for installation and testing in a commercial die casting operation. Three thousand one hundred oilpump covers were cast in A380 aluminum against the inserts at injection pressures of approximately $11,000 \mathrm{psi}$ and temperatures ranging from $1207-1228^{\circ} \mathrm{F}$.

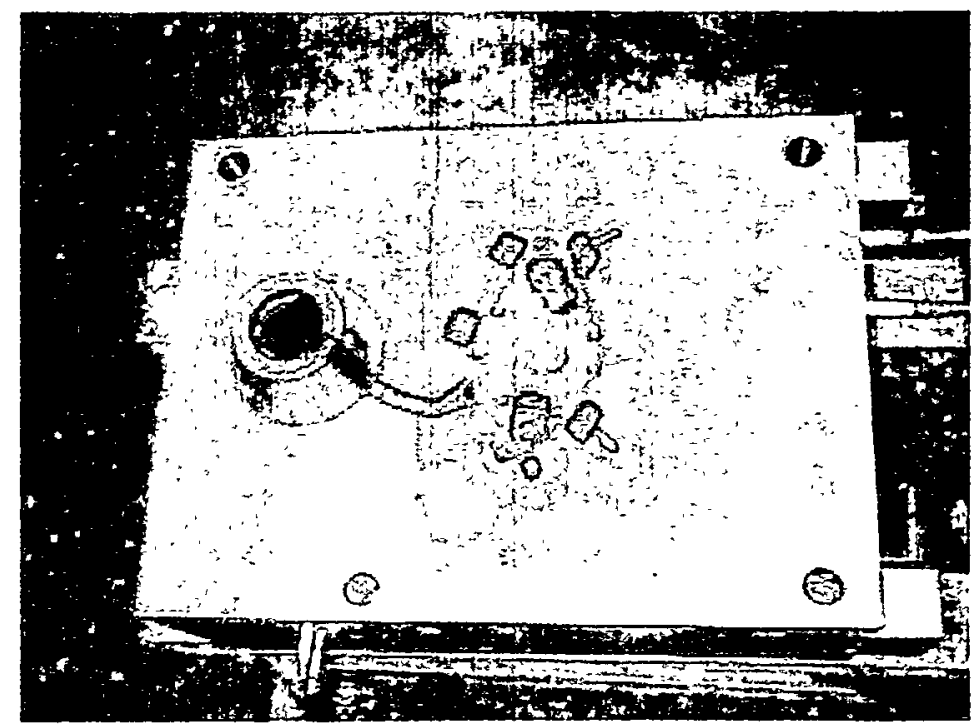

Figure 5: The investment cast ejector half insert in the fabricated holding block 


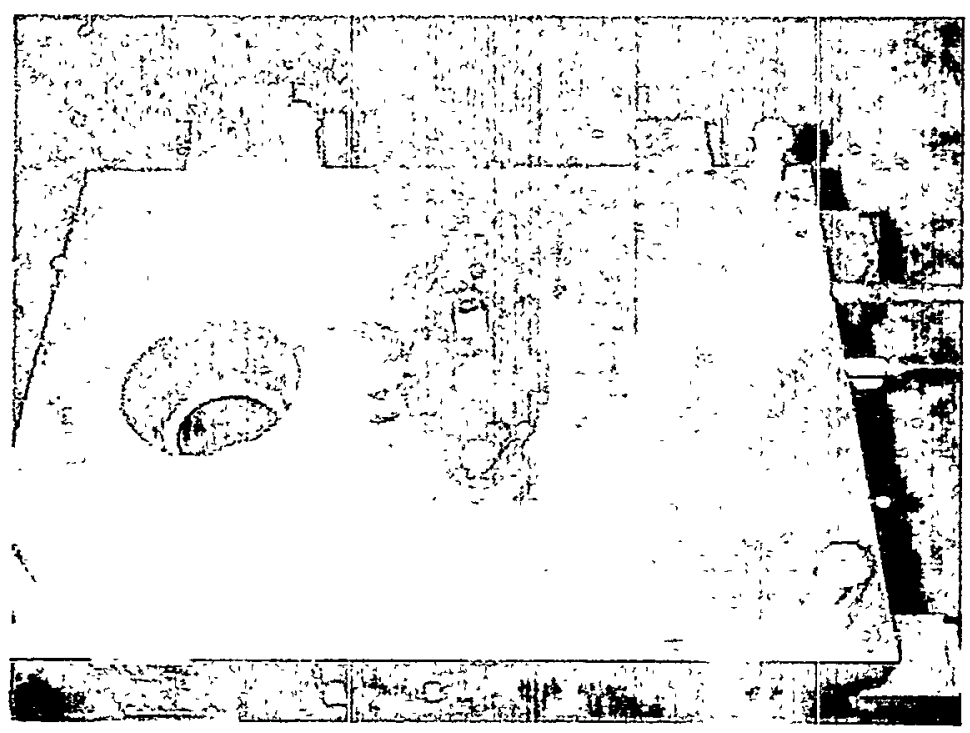

Figure 6: The machined cover half insert in the fabricated hold block.

At the end of the run no visible difference could be detected between the cast and machined inserts, Fig. 7. Inspection by Atols concluded that the cast insert performed identically to the machined insert. Both inserts had no indications of heat checking or degradation. The only difference in the resulting aluminum parts was the surface roughness difference from the two inserts. As previously mentioned, the cast insert only had a rough sand blast finish, thus, resulting in a rougher surface than the machined surface. There are a variety of simple surface finishing techniques available that would vastly improve the finish on the insert and the subsequent casting. 
a)

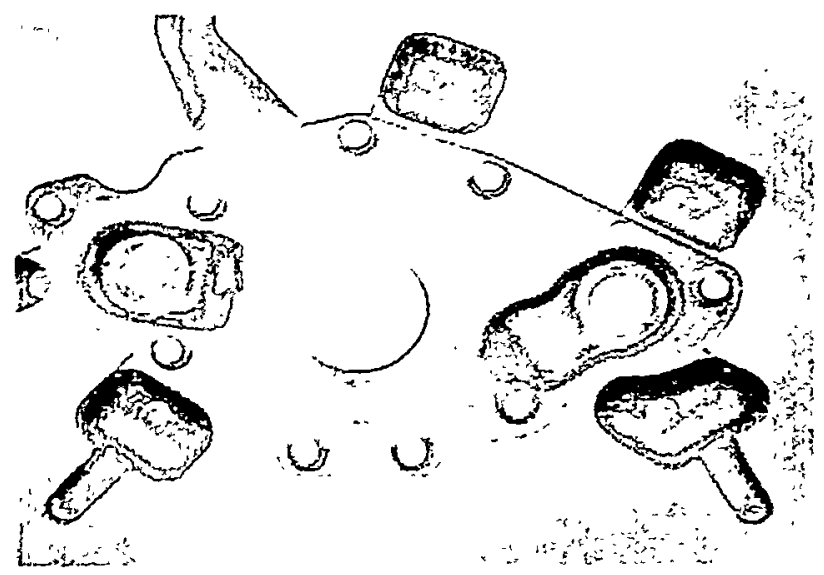

b)

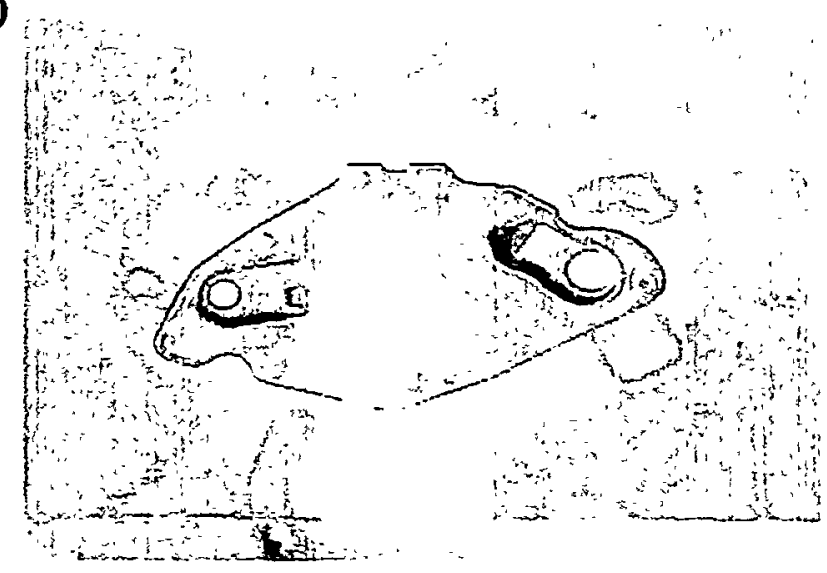

Figure 7: Both insert halves after 3,100 shots of aluminum with no visible difference no indications of heat checks or degradation; a)cast injector insert; b) machined stationary insert

\section{Conclusions}

It has been demonstrated that an investment casting of high quality and a proper heat treatment (including HIP) can perform satisfactorily as an insert in a die casting environment. This is an important accomplishment because it demonstrates to the die casting community that investment castings can be used in a process where only wrought product has existed to date.

The valve body insert that Precision Castparts Corporation (PCC) is currently casting for USAMP is of sufficient complexity to demonstrate the advantage of casting complex shapes versus machining. The valve body insert is also comprised of thinner cross sections (less than $0.25 \mathrm{in}$.) that are more amenable to the investment casting process. The insert contains no trapped volumes which is advantageous for the SLA build. These factors lead to the insert being a prime candidate to demonstrate achievable dimensional accuracy and to build on the success of the oilpump insert. It is extremely important to demonstrate as many examples as possible of cast inserts being used in the die casting operation to gain acceptance from the die casting community. 


\section{DISTRIBUTION:}

1 Art Schneider

Supervisor - Casting Department

Chrysler Corp.

800 Chrysler Dr. CIMS 481-01-41

Auburn Hills, MI 48326-2757

1 Larry Kopka

Diecasting \& Materials Engineering Chrysler Corp.

800 Chrysler Dr. CIMS 482-00-16

Auburn Hills, MI 48326-2757

1 Gary Ward

Casting Engineer

GM Powertrain Division

General Motors Corporation

Ypsilanti Transmission Plant

Ecorse and Wiard Streets

Ypsilanti, MI 48198-6198

1 Larry Ouimet

Staff Project Engineer

Casting \& Matl Processing

Manufacturing Building A/MD-36

MC 480-109-324

30300 Mound Road

Warren, MI 48090-9040

1 Dawn White

Principal Engineering Specialist

Ford Motor Company

Ford Research Laboratory

P. O. Box 2053-MD 3153 SRL

Dearborn, MI 48121-2053
1 Dan Wilkosz

Research Engineer

Ford Motor Company

MD 2313 SRL

P. O. Box 2053

Dearborn, MI 48121-2053

1 Robert Eppich

NADCA

P. O. Box 1003

Port Lavaca, TX 77979

$1 \quad$ MS 0958 Brian Pardo, 1484

1 MS 1434 A. K. Hays, 1800

1 MS 1434 J. Jellison, 1803

1 MS 9018 Cen Tech Files, 8940-2

2 MS 0899 Technical Library, 4916

$1 \quad$ MS 0619 Rev. \& App Desk, 00111 for DOE/OSTI 